\title{
Is the STEM Approach Useful in Teaching Mathematics? Evaluating the Views of Mathematics Teachers
}

\author{
Eyüp Sevimli ${ }^{1 *}$, Emin Ünal ${ }^{2}$ \\ ${ }^{1}$ Faculty of Educational Sciences, Istanbul Medeniyet University, Istanbul, TURKEY \\ ${ }_{2}^{2}$ Alacabal Secondary School, Turkish Ministry of National Education, Tokat, TURKEY
}

*Corresponding Author: eyup.sevimli@medeniyet.edu.tr

Citation: Sevimli, E. and Ünal, E. (2022). Is the STEM Approach Useful in Teaching Mathematics? Evaluating the Views of Mathematics Teachers. European Journal of STEM Education, 7(1), 01. https://doi.org/10.20897/ejsteme/11775

Published: February 18, 2022

\begin{abstract}
The STEM approach, which has been included in the education literature with increasing value in the last decade, has also drawn researchers' attention to the process of learning and teaching mathematics. In this study, the views of mathematics teachers, who were involved in in-services STEM-training, were evaluated under the themes of integration with the curriculum, limitations in implementation, and attitude development. A qualitative case study was carried out with 36 secondary school mathematics teachers. Data were collected with a questionnaire form two different types of STEM tasks (engineering design sets and coding) and analyzed with descriptive statistics. The results of the study showed that the participants' views on the usefulness of STEM tasks in mathematics teaching are positive, but they have difficulties with linking the tasks to the mathematics curriculum. Participants find coding tasks more applicable than the engineering design and building tasks. Suggestions are made for teacher education and textbook development.
\end{abstract}

Keywords: STEM, mathematics teacher, coding tasks, engineering tasks

\section{INTRODUCTION}

One of the goals of education is to prepare individuals for the competencies needed in the 21st century and to train them well-equipped in this sense. Several revisions are made in different education systems around the world to improve skills such as creativity, critical thinking, problem-solving, and digital literacy (MoNE, 2016; NCTM, 2000). The STEM (Science, Technology, Engineering, and Mathematics) approach provides educational content that will enable future generations to be successful in STEM fields and helps the transition into digitalization and thinking on the basis of technology (NRC, 2011; Stohlmann et al., 2012; TUBITAK, 2016). Therefore, so as to obtain the competencies that the 21st century requires, training teachers for STEM education and preparing programs in accordance with the content required by interdisciplinary relationships are two important issues. The STEM-based curriculum not only aims to lead students to solve real-world problems but, thanks to their sufficient education and equipment in the field of STEM, also makes them future implementers of such curricula (Wang, 2013). Unlike the learning outcomes-based perspective of the traditional curriculum, the STEM education approach has an integrated skills-based philosophy in mathematics education (Bybee, 2010; NRC, 2011). Another key component that makes an educational approach or curriculum useful is how effectively this approach is used by teachers in their teaching practice. However, it remains unclear how much the STEM approach is adopted by the practitioner teachers in mathematics education and how well this approach is compatible with the current mathematics curriculum. Various studies in the related literature mainly consist of the developed scales and 
attitudes towards STEM education and in some other studies, science teachers' views are evaluated (El-Deghaidy et al., 2017; Li et al., 2020; Tseng et al., 2013). Among all these studies, there is limited research on mathematics, which is one of the stakeholders of STEM disciplines. However, it is important to consider the mathematics discipline, which students have difficulty in associating with daily life, but which also includes STEM skills such as modeling, measuring, and using numbers, within the STEM approach. For this reason, the aim of this study is to evaluate the views of mathematics teachers about using STEM tasks in their teaching practices. In the present study, answers to the following two questions were sought:

1. What are the views of mathematics teachers about the usefulness of STEM tasks in secondary school mathematics teaching?

2. Which mathematical skills can be improved with STEM tasks according to the views of mathematics teachers?

\section{Conceptual Framework}

\section{What is STEM education?}

STEM, which emerged as a product of the initiatives of some institutions and foundations in the early 1990s to solve various problems in the American workforce, has now found a place in education policies globally (NRC, 2011). STEM education has become more important as it is developed as an integrated effort that eliminates the traditional barriers between science, technology, engineering and mathematics, and attaches importance to innovative skills with the help of the contemporary technology (Kennedy and Odell, 2014). There are different definitions for STEM education in the literature. According to Bybee (2010), STEM education is an approach to improve the use of technology and designing products in science and mathematics teaching so as to increase students' understanding of how things work. Some other definitions of STEM education are: a multidisciplinary model that helps the development of skills in science, technology, engineering, and mathematics (Tsupros et al., 2009); the new generation curriculum for associating two or more STEM disciplines (Kelley and Knowles, 2016); simultaneous teaching of science and mathematics contents through the use of technology/engineering design (Kang et al., 2013). As stated above, although there are various definitions regarding STEM education, the common feature of these definitions is that they emphasize "interdisciplinary nature". Apart from other educational approaches, STEM education is skills-oriented and integrative.

Many studies in the literature examine the impact of STEM education on teachers' perceptions or/and students' skills (Bergsten and Frejd, 2019; Margot and Kettler, 2019; Park et al., 2016; Wang et al., 2011). The STEM approach, which finds a place in the field of education with a pragmatic agenda, has a claim to contribute to the development of skills that will be needed especially in the 21 st century. These skills can be listed as critical thinking, collaboration, leadership, mathematical modeling, and productivity (Drake, 2012; Li et al., 2020; Stohlmann et al., 2012). According to Stohlmann et al. (2012), as the integration of STEM subjects into the curriculum increases, students can improve their critical thinking and problem-solving skills more effectively. Comparisons of international perspectives on the different policies and programs of each country show that many countries place STEM education in their systems with an increasing interest (Marginson et al., 2013). For instance, the Scientific and Technological Research Council of Turkey (TUBITAK), aims to create a "welfare society" that is literate in every subject of technology and science, and able to produce new technologies, use them consciously and transform the technological developments for the benefit of the greater society and economy (TUBITAK, 2016). To contribute to the training tasks of participants, some universities in Turkey have started to introduce STEM centers from which teachers and prospective teachers can benefit. Today, certificate programs are carried out in the Continuous Education Centers of more than 20 universities in Turkey to provide teachers with professional awareness and the workshop skills that they can use in their classrooms when it comes to STEM education. Although STEM terminology was not included directly in the mathematics curriculum of Turkey, attention is drawn to the interdisciplinary integration in the teaching process (MoNE, 2018). With the interest in STEM education in the field, researchers started to discuss the role of teachers in this approach.

\section{Teachers' perception on STEM education}

It is important to evaluate teachers' perceptions to understand the usefulness of an educational approach or method in classroom practice. STEM education research conducted with teachers' perceptions in the relevant literature can be grouped under two headings. These are STEM practices of teachers and teachers' attitudes and/or views on STEM education. In these studies, particularly the teaching of science concepts or the views of science teachers were considered as the central discipline in STEM education. In one of these studies, Wang et al. (2011) found that STEM professional development programs for teachers provided more opportunities and connections on how to use STEM integration for teaching their disciplines. El-Deghaidy et al. (2017), in their study about 
evaluating the science teachers' views regarding STEM pedagogy, found that teachers have concerns about their under-preparedness to enact STEM practices.

In recent years a considerable number of surveyed science teachers' attitudes towards STEM education, but few researchers have addressed the views of mathematics teachers in STEM environment (El-Deghaidy et al., 2017; Margot and Kettler, 2019; Tseng et al., 2013). In the literature concerning the processes and the evaluations of the STEM education approach in mathematics teaching, researchers generally have addressed the issues of students' mathematical achievement or mathematical modeling (Bicer et al., 2015; Stohlmann, 2017, Ozdemir et al., 2018). In one of the studies about academic achievement, Bicer et al. (2015) compare schools with and without STEM education in the USA in the context of 9th-grade mathematics achievement. The results of the study show that the mathematics achievement of 9th-grade students in schools applying STEM education is higher than those of the students at the same grade level in a school not practicing STEM. The contribution of STEM education to mathematics achievement is still discussed (English, 2016). Unlike other disciplines, mathematics is assessed by the legitimate principles of the discipline itself, while other disciplines are used as motivational contexts or application areas of mathematical methods (Bergsten and Frejd, 2019). Mathematics is already embedded in the process of evaluating disciplines such as science and engineering. A study revealing the contributions of the STEM education approach in terms of mathematical skills development has not been available in the reviewed literature.

\section{STEM tasks and curriculum integration}

The most important challenge encountered in STEM education is the problem of curriculum integration. Sometimes a new curriculum is developed to overcome this problem, but if STEM activities are integrated into the existing curriculum the current curriculum and the role of teachers needs to be monitored more closely (Bergsten and Frejd, 2019). The skills-oriented advantages of STEM education can benefit from teachers who are wellequipped in STEM education (Wang, 2013). The most important part with which teachers may have difficulties and prove inadequate during the implementation of STEM education would be the lack of content knowledge and attitudes towards integrability of STEM disciplines (Estapa and Tank, 2017; Park et al., 2016). Ozdemir et al. (2018) found that teachers have been incompetent in integrating and interpreting different disciplines, which is the most important part of STEM education. Wang et al. (2011), on the other hand, investigated teachers' beliefs about the use of integrated STEM from the perspective of branch teachers, and they determined that while science, mathematics, and engineering teachers have a common problem-solving process, STEM teachers in different disciplines have different perceptions about integrating STEM, thus emphasizing the variety of skills in applications.

The usefulness of STEM education also depends on the type of tasks or activities used in the integration process. Engineering design sets, or accessible materials may be used when developing a task in STEM learning environments. Another approach considered influential in teaching mathematics through STEM education is coding, as a result of which recently more attention has been given to coding education in STEM research. It is not yet known whether the coding tasks carried out within the framework of STEM education are effective for teaching mathematics. However, studies conducted with a coding program such as Scratch or Mblock can offer us an idea in this sense. Calder (2018) evaluated the effect of Scratch on 10-year-old students' mathematical skills and the findings showed that mathematical thinking, including geometry and problem-solving processes, was facilitated through these applications. In another study conducted with a similar purpose, Iskrenovic-Momcilovic (2020) examined the effectiveness of Scratch's application in mathematics in the study of basic geometric shapes and found that the coding tasks, which are added to the curriculum, have allowed mathematics to become more interesting to students. In the experimental research evaluating the coding tasks developed by STEM-trained preservice mathematics teachers, it has been determined that the participants tended to develop tasks for the domains of geometry and measurement and focused mostly on algorithmic thinking and visualization skills within the task (Ozdemir et al., 2018).

In summary, with the increasing interest of researchers in STEM education and the international recognition that this approach has gained, other questions that need to be answered are how these efforts are reflected in classroom practice and what teachers' views are about the usefulness of STEM education must. In this sense, research that examines how mathematics teachers, as the implementers of the curriculum and stakeholders of the STEM disciplines, practice their STEM education in teaching environments is crucial for a direct reflection on the learning-teaching processes. 

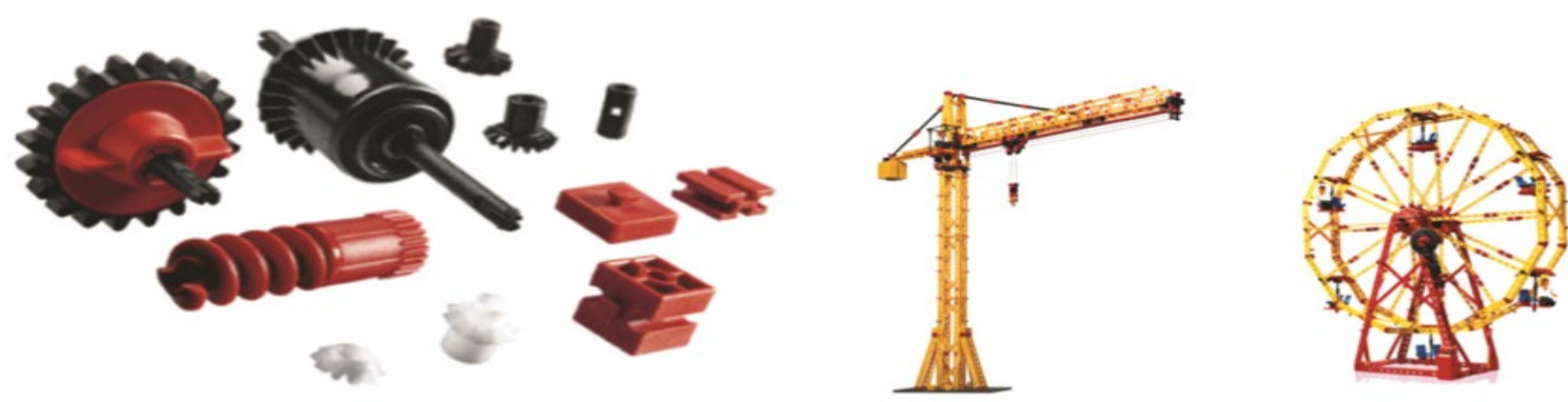

Figure 1. Some parts of Fischertechnik engineering sets

\section{METHOD}

\section{Research Model and Participants}

This research focuses on a detailed and comprehensive examination of teachers' views and practices regarding an educational approach (STEM). The case study design was used in this research to understand the skills and mathematical subjects that teachers consider when using STEM tasks in their classroom practice. The case study is a detailed examination of a phenomenon with a holistic approach, and it is used by researchers to understand a situation using "how and why" questions (Yildirim and Simsek, 2013). Qualitative data from case studies must enable in-depth analysis and shed light on the contribution of other components that occur around the case. Unlike survey design, the case study design deals with a phenomenon occurring in and around a group of participants that is investigated in-depth and with multiple tools. The case in this study is the usefulness of STEM tasks in teaching practice.

For the opinions expressed by the participants about an educational approach to be representative of an authentic situation, the participants must be involved in this education beforehand. Therefore, the participants included in this study were chosen from among the mathematics teachers who participated in an in-service professional development program for STEM education. Purposeful sampling technique, which is appropriate to the qualitative research paradigm, was utilized in the present research because purposeful sampling provides rich data that can be analyzed in detail and used for the evaluation of situations (Creswell, 2009). The participants of this study are thirty-six secondary school mathematics teachers working in the Black Sea region of Turkey. For maximizing representativeness of the sampling in the study, each of the participants was selected from a different secondary school. As only a limited number of teachers can be provided with face-to-face STEM education within the framework of in-service training, this number represents a high regional participation. The participants were expected to have taken part in the previous two years in the in-service training programs, which were especially designed for the subject of STEM education under the name of Professional Development Program by the General Directorate of Teacher Training and Development of the Ministry of Education in Turkey. The in-service training program is carried out by academics who are experts in STEM Education and lasts for a week with the participation of teachers from different disciplines. The STEM training is carried out in two stages, basic and advanced. The basic level includes information about STEM education, recognizing STEM materials, understanding the teaching methods and techniques that can be used during STEM education and information about how STEM can be integrated into lessons, the advanced stage includes skills such as using a 3D printer, robotic coding, and workshop applications, and is organized for the teachers who are above basic level. Twenty of the teachers participating in the study received basic level STEM education, and the rest (sixteen participants) took the advanced level.

\section{Data Collection Tools}

In this study, questionnaires and interviews were used to collect data. The STEM-Usefulness Form was applied as a questionnaire to determine the participants' views on the integration of STEM tasks in the curriculum. The STEM-Usefulness Form includes items, tasks, and short answer questions to evaluate the views of secondary school mathematics teachers about the usefulness of STEM tasks. The form includes two types of tasks: three on Engineering Design and Building (EDB) tasks and three on coding. Thus, the usefulness of STEM contents in the teaching process according to the type of task was evaluated within the framework of the participants' views. The tasks in the STEM-Usefulness Form were selected from the "Secondary School STEM Task and Project Book" by Altun and Yildirim (2015).

The EDB tasks are the type of tasks in which students create a product using the plug-in parts (Fischertechnik) prepared for the STEM learning environment (Figure 1). 


\section{The EDB task: Our Security is in Your Hands}

What I Will Learn: You will install electrical circuits in this project. You will use the electrical circuits you have installed for communication, and you will see the technological applications of science. Also, you will learn about cryptology (encryption), one of the fields of mathematics, and you will develop your encryption systems.

Duration: 5 hours


Figure 2. The Introduction to the 'Our Security is in Your Hands' task and the visual guide to assembling parts

Some stages of the task named 'Our Security is in Your Hands', which is one of the EDB tasks in the STEMUsefulness Form, are presented in Figure 2. The task begins with a brief introduction to the purpose of the task, what kind of mathematical skills can be achieved at the end of it, and its duration (Figure 2).

The following sections describe what to do step by step, the topics of investigation, and which parts to use. The process of assembling the necessary parts and creating the product is also visually included in the tasks. The other two EDB tasks are "The Ferris Wheel" and "Producing the Domestic Car". The coding tasks, on the other hand, create products on traffic signals, wind turbines, and self-parking by adding an open-source microcontroller platform to the engineering sets via Mblock and Arduino programming.

According to Buyukozturk (2005), there are three critical stages when preparing a questionnaire. These are

a. obtaining expert opinion after writing the items,

b. revising the items according to the pre-application results, and

c. ensuring the internal consistency of the questionnaire.

In the process of preparing the questionnaire items in the form, first of all, the mathematics teachers involved in STEM education as a part of the pilot study were interviewed and as a result of these interviews, the draft form of the items was created. The positive and negative statements about the usefulness of the STEM tasks were placed in the form. The items in the form were selected from the prototype statements that question the usability of teaching material in the curriculum that have been used before. Six of the 14 questionnaire items related to integration in the curriculum, limitations of the implementation, and attitude development. Participants were expected to justify their answers. The form was examined by two experts with $\mathrm{PhD}$ in mathematics and science education. After the pilot study, the questions in the form took their final version.

After the application of the STEM-Usefulness Form to all participants, semi-structured interviews were conducted with ten teachers selected from the participant group to examine the problem which is investigated more deeply and to present the results more strongly. Participants were selected according to the level of STEM education they had received (five at the basic level, and five at the advanced level) and to represent the variety of responses in the STEM-Usefulness Form. In preparing the interview form, STEM-Usefulness Form questions were used for reference depending on the subject investigated, and the studies in the literature were utilized to enable the researcher to obtain more detailed information about the subject and ask more questions when necessary. 


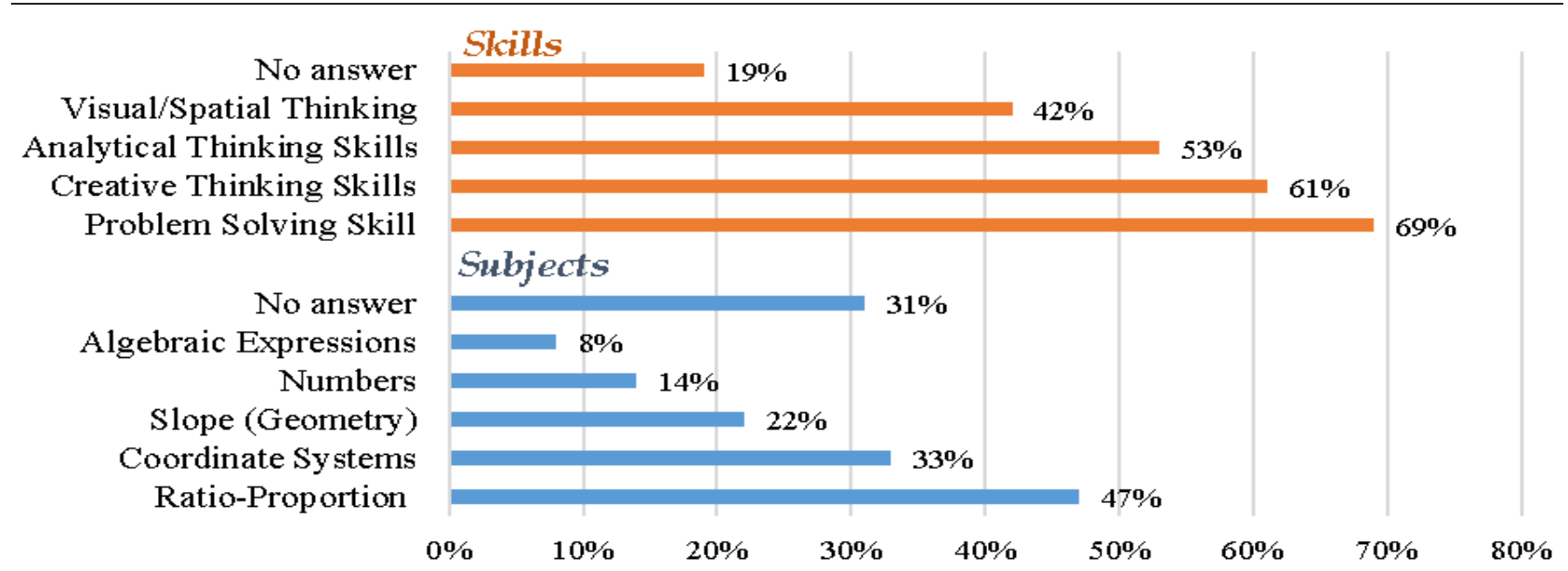

Figure 3. The distribution of subjects and skills integrated within STEM tasks

\section{Data Analysis}

Descriptive statistics and content analysis have been used to analyze the data obtained from the STEMUsefulness Form and to evaluate the data from the semi-structured interviews respectively. In the STEMUsefulness Form, there are Likert-type items of questionnaires and questions requiring short answers, along with spaces where participants can express their opinions for two types of tasks they have undertaken. The data from the STEM-Usefulness Form have been evaluated under the following labels: curriculum integration $\left(1^{\text {st }}\right.$ and $2^{\text {nd }}$ items along with short-answer question 7), limitations in the implementation ( $3^{\text {rd }}$ and $4^{\text {th }}$ items along with shortanswer question 8), and developing positive attitude ( $5^{\text {th }}$ and $6^{\text {th }}$ items along with short-answer question 9). Comparisons have been made based on the participants' responses to the task type according to the STEM education level they received, and the findings are presented as percentages and frequency. In the content analysis the data were coded and grouped in categories according to the association of STEM tasks with specific mathematical subjects and mathematical skills (see Figure 3). Cronbach's alpha was calculated $(\alpha=.82)$ to determine the internal consistency of the application. After the interview, the transcription was read and confirmed by the participants, and false findings and comments were prevented.

\section{RESULTS}

The findings have been evaluated under the following headings:

1. The views on integration of the tasks in the curriculum,

2. The limitations of implementation of the tasks, and

3. The role of the tasks in the process of attitude development.

In this sense, the STEM-Usefulness Form and interview findings were integrated and presented under relevant headings.

\section{The Views on the Integration of the Tasks in the Curriculum}

When the responses to the first and second item in the STEM-Usefulness Form are examined, a majority of participants stated that both EDB and coding are suitable, but EDB tasks are considered to be more compatible with the mathematical skills in the secondary school curriculum compared to coding tasks (see Table 1). However, the percentage of participants considered to use these tasks in their mathematics course was lower for both task types ( $2^{\text {nd }}$ item). For instance, $64 \%$ of the participants' state that EDB tasks are compatible with the curriculum, while the rate of participants who consider using these tasks in mathematics courses decreases. The data also show that the STEM tasks that include coding are more likely to be integrate into the mathematics curriculum than the EDB tasks. A large minority of participants, about 34\%, think that both EDB and coding tasks may not be compatible with the mathematics curriculum. This is in agreement with the findings of the interviews, were seven of the ten participants stated that they have a positive attitude towards STEM tasks, whether coding or EDB, because they emphasize the interdisciplinary relations and contribute to the spiral quality of the curriculum, i.e., the relationship of the new learning with the old learning in different contexts. The first participant (P-1) stated that her awareness of the interdisciplinary approaches has increased as a result of the STEM teaching certificate that she received within the scope of in-service training, and that the tasks presented in this study have encouraged her to use mathematics in an interdisciplinary fashion. 
European Journal of STEM Education, 2022, 7(1), 01

Table 1. The frequency and percentage distribution of the data in the STEM-Usefulness Form

\begin{tabular}{|c|c|c|c|c|c|}
\hline \multirow{2}{*}{ No } & \multirow{2}{*}{ Questionnaire items } & \multicolumn{2}{|c|}{ EDB tasks } & \multicolumn{2}{|c|}{ Coding tasks } \\
\hline & & Yes & No & Yes & No \\
\hline 1 & $\begin{array}{l}\text { The task is suitable for the mathematical skills aimed at the secondary } \\
\text { level mathematics curriculum. }\end{array}$ & $23(64 \%)$ & $13(36 \%)$ & $28(78 \%)$ & $8(22 \%)$ \\
\hline 2 & I consider applying the task in my mathematics courses. & $17(47 \%)$ & $19(53 \%)$ & $23(64 \%)$ & $13(36 \%)$ \\
\hline 3 & $\begin{array}{l}\text { I may have time management problems during implementation of the } \\
\text { tasks. }\end{array}$ & $25(69 \%)$ & $11(31 \%)$ & $21(58 \%)$ & $15(42 \%)$ \\
\hline 4 & I may have a lack of material during implementation of the task. & $24(67 \%)$ & $12(33 \%)$ & $23(64 \%)$ & $13(36 \%)$ \\
\hline 5 & I think the task will support students' mathematical development. & $27(75 \%)$ & $9(25 \%)$ & $29(81 \%)$ & $7(19 \%)$ \\
\hline 6 & The task positively affects students' attitudes towards mathematics. & $21(58 \%)$ & $15(42 \%)$ & $30(83 \%)$ & $6(17 \%)$ \\
\hline
\end{tabular}

P-1: The main purpose of STEM education is to present a product design by using mathematics, science, and technology together. Of course, while preparing the design of this product, some mathematical skills are necessary, so I think that tasks can be used in the curriculum ... Especially EDB tasks exemplify the interaction of mathematics with science discipline.

On the other hand, the participants who argued that the tasks may not be compatible with the mathematics curriculum put forward that, since the curriculum is learning objective-oriented, prioritizing the skills championed by the STEM approach may timewise prove difficult along with teaching the tasks required by the curriculum. For example, P-8 stated that it would be more appropriate to carry out STEM tasks outside the current mathematics course and referred to the subject-time relationship in the curriculum to support this view. P-4 likewise stated that it would be more convenient and beneficial to engage in STEM tasks with students who are willing and partly successful in this field, instead of applying them to all students in regular classes. Participants who argued that the tasks may not be compatible with the curriculum, jointly argued that STEM tasks could be given in out-of-school learning environments to students interested in them, as seen below:

P-8: It can be used in teaching mathematics, but how efficient would it be? A STEM task takes four to five hours, but mathematics classes last an hour or two. So, it is a bit difficult with the current curriculum. But I think that including STEM tasks in a workshop environment or outside classes is very useful for teaching mathematics.

P-4: I think that STEM education should not be employed for all children, but for the talented ones, who should be educated in out-of-school learning environments such as science and art centers. I think this training would be difficult for students who have displayed very poor performances.

Question 7 in the STEM-Usefulness Form asked participants which STEM tasks presented in the form could be integrated with which subjects and skills already existing in the mathematics curriculum. The answers to this question are presented in Figure 3. It was observed that the participants associated the given tasks most frequently with the subjects of ratio-proportion $(47 \%)$ and the coordinate system $(33 \%)$ in the curriculum. The participants had difficulty integrating STEM tasks with mathematics subjects because 31\% of them did not answer the seventh question. The participants were less reluctant to associate STEM tasks with mathematical skills. $56 \%$ of the participants associated the tasks with more than one skill. More than half of the participants stated that the tasks presented in the form would contribute positively to the development of problem-solving (69\%), creative thinking (61\%), and/or analytical thinking skills (53\%).

\section{The Limitations in the Implementation of the Tasks}

When the participants' responses to the STEM-Usefulness Form are evaluated within the theme of "limitations in the implementation", it becomes clear that approximately two-thirds of the participants were concerned about experiencing either time management issues or material shortages when using either EDB tasks or coding tasks in classroom practice (see Table 1).

To identify other constraints related to "material and time management" factors that limit the usefulness of EDB tasks in practice, question 8 inquired into other possible difficulties that might be experienced during the implementation of the tasks. The two most common reactions could be coded as the task being "difficult to design for each mathematical skill" (64\%) and "requiring material setup or knowledge in software usage" (47\%). Likewise, in the semi-structured interview findings, the participants emphasized that it would be difficult to develop a task suitable for each mathematical skill in the curriculum. Three participants stated that another difficulty in implementing STEM tasks in the mathematics classroom may be encountered during the course's assessment and evaluation process, illustrated by the following quotes: 
P-7: STEM tasks are mostly considered regarding science disciplines, but tasks that support problemsolving skills in mathematics could be designed, too. Therefore, I think they could be used in mathematics. But it is difficult to design a STEM task for each mathematical skill.

P-1: Both the fact that our curriculum and examination system are not suitable for integrating STEM in it and that we lack time and materials cause difficulties for us in practice because of our deficiencies, not to mention the students'.

\section{The Role of the Tasks in the Process of Attitude Development}

The responses to the fifth and the sixth questionnaire items have been used to determine whether the tasks contributed positively to the process of attitude development. $75 \%$ (27 participants) and 81\% (13 participants) of the participants stated that the EDB tasks and the coding tasks would support the mathematical development of students (see Table 1). The sixth item of the questionnaire evaluated the effects of the tasks on students' attitudes towards mathematics. $58 \%$ of the participants stated that EDB tasks may contribute to the process of developing positive attitudes towards mathematics, while $42 \%$ claimed the opposite. For coding tasks, this was much higher: $83 \%$ stated that students could develop a positive attitude towards mathematics.

In addition to the type of task, the level of the STEM education received by the participants in the in-service training program may also affect the attitudes towards the usefulness of the STEM tasks. Question 9 in the form asked the participants to evaluate the STEM education level they had received in terms of its utility in teaching mathematics. The basic level STEM education was found sufficient by approximately two-thirds of the participants $(68 \%)$, while the advanced level by $85 \%$ of the participants. In the interviews, the participants who received STEM education at a basic level could describe what they needed more. Two remarks (from P-5 and P-6 below) indicate that they may need more practice and that an advanced level may be necessary to cover the whole mathematics curriculum.

P-5: I cannot use [STEM] due to the first training I received, because we could not practice it. I know that STEM education will contribute to mathematics, but I have not been able to move on to the implementation phase in my teaching practices yet. I consider [implementing STEM] once I receive further education.

P-6: Since the education I received was at the basic level, I could not use it a lot, only a little in mathematics applications.

Participants who had received an advanced level STEM education were more willing to implement the tasks included in the form into classroom practice. P-10 illustrated how EDB tasks can be used in classrooms in cooperation with the subject of ratio-proportion and for the development of creative thinking skills. P-8 stated that using coding tasks in mathematics classes would offer the opportunity to associate mathematics with realworld problems, therefore contributing positively to the students' attitude towards mathematics.

P-10: I worked with seventh-grade students at school and carried out a practice about the ratioproportion that included wheels. I gave the children wheels with different diameters, introduced the engineering sets, and then gave the instructions and waited for the children to do it. It proceeded as a group investigation, resulting in many authentic ideas and discussions. We thus had a practice related to other disciplines, especially science.

P-8: I would like to mention my STEM task as an example. We performed a task of pudding-making for diabetes patients with my seventh-grade students. When cooking the desert, they made a cup with a 3D printer. They were very interested and were informed about diabetes. Using mathematics, they calculated how much sugar they should put in. With this, they also saw that mathematics is used in daily life.

\section{DISCUSSION}

The main problem for which the answer is sought in this study is to evaluate views of mathematics teachers about the usefulness of STEM tasks in secondary school mathematics teaching. The findings in the present study demonstrated that the STEM education approach is considered important by the participants, but they still see difficulties for using STEM tasks in the classroom. We can conclude that the support in theory is higher than the support in practice. An important constraint is linking STEM tasks to specific content or skills of the mathematics curriculum (31\% of the participants did not answer question 7). The lack of explicit indications for STEM 
education in the mathematics curriculum may also negatively affect the motivation of teachers who are the executives of the curriculum. Wang (2013) emphasized that teachers' biggest problems are time constraints and material and technological deficiencies during STEM applications, which cause disadvantages in the implementation of STEM tasks in lessons. Although some materials for designing and implementing STEM tasks can be obtained easily, other technological components remain difficult to find or manufacture specifically.

The participants who stated that STEM tasks would develop a positive attitude for mathematics emphasized establishing interdisciplinary relationships and using mathematics in daily-life problems. Indeed, in other research evaluating the effectiveness of the STEM approach with groups of teachers teaching different subjects, it has been pointed out that if students create a product by applying their knowledge of different subjects do daily-life problems, they can develop self-confidence, which will increase their motivation towards the STEM subjects (Kim et al., 2015). Likewise, the researchers are aware that the STEM approach is an integrated field and a productoriented, pragmatist education approach that merges the power of disciplines, rather than favoring one over the other.

It is natural that the teaching habits or experiences of teachers may cause resistance towards a new approach. This study related enthusiasm or resistance to the type of task. Mathematics teachers perceive coding tasks to be more clearly linked to the contents of the mathematics curriculum than EDB tasks. This could be partly explained by the fact that coding and robotics training was part of the advanced in-service training. Or, it may take experience to appreciate the contribution that science or engineering tasks can make to mathematics. Park et al. (2016), is a similar study, found that experienced Korean teachers have a positive view on the role of STEAM education. Other researchers argue that the contribution of mathematical knowledge and/or skills to other learning outcomes should be made more explicit to support STEM integration in the curriculum (English, 2016; Shaughnessy, 2013). Mathematical modeling of daily-life problems, which already has a place in the secondary mathematics curriculum of Turkey (MoNE, 2018), may be a good starting point for STEM integration. Modeling can be one of the most powerful tools of mathematics in interdisciplinary integration (Stohlmann, 2017). We observed that the mathematics teachers in this study associate STEM tasks with mathematical skills and generally prioritize problemsolving skills. Better, more creative and more compatible products may be obtained as a result of the integration of mathematical modeling with design and technology.

Our study confirms what similar studies have also shown, namely that STEM tasks are time-consuming compared to other mathematical tasks (Ozdemir et al., 2018). The fact that the participants who had not received support for a STEM education approach during their undergraduate education voluntarily wanted to receive STEM education within the scope of in-service training shows that the interest in this issue has increased.

Professional development on STEM education provided at a basic level raises awareness, but teachers apparently still need advanced level training and be educated in coding and robotics for using STEM tasks which are made up of engineering sets, e.g., plug-in parts, in classroom practice. Other studies also indicate that coding activities through interactive software such as Scratch can increase both student attitude and skills (i.e., problemsolving, geometrical thinking) in mathematics teaching (Calder, 2018, Iskrenovic-Momcilovic, 2020). This study confirms that coding tasks that are embedded in STEM education are found more interesting to teachers. Therefore, we suggest to include this topic in pre-service teacher education courses, preferably at an advanced level STEM education with regard to their branches, so that coding can be integrated in the curriculum.

In this study, participants stated they had difficulty in establishing a relationship between STEM tasks and mathematical skills. As mathematics teachers, they naturally prefer tasks to use in their teaching that fit the mathematics curriculum. The literature shows that coding tasks used in mathematics contribute to algorithmic thinking, geometrical thinking or reasoning (Calder, 2018; Iskrenovic-Momcilovic, 2020; Ozdemir et al., 2018). These skills are also important in STEM education in general (Bybee, 2010) and in the engineering design tasks derived from the Fischer Technik sets (Yildirim and Altun, 2015). Estapa and Tank (2017) state that content knowledge and beliefs are important for teachers that make decisions about integrated STEM in engineering challenges. However, the participants thought that the tasks could be used for only a few subjects, such as ratio and proportion or coordinate system. Almost one-third of the participants did not answer the question regarding the subjects in secondary school mathematics curriculum that may be compatible with STEM tasks. Furthermore, the interviews show participants believing that STEM tasks are mostly related to subjects in the science curriculum, thus leaving mathematics out. This mindset may be a cause for the difficulties with integrating STEM tasks with the skills in the secondary school mathematics curriculum. In the Turkish secondary education level, STEM education has been placed in the science curricula (MoNE, 2018). The fact that STEM tasks are not included in the curriculum and in mathematics textbooks may cause teachers not to be open for the idea of interdisciplinary integration in their teaching practice. Considering these findings, providing STEM education to teachers by itself is not sufficient for the implementation of this educational approach in the teaching practices. The mathematics curriculum and textbooks should be updated as well. 


\section{CONCLUSION}

This study shows that mathematics teachers' opinions on integration are related to the task types. Mathematics teachers favor coding tasks over EDB tasks. Although the mathematics teachers in our study have a positive attitude towards teaching integrated STEM, they have a lower motivation to use these tasks in their classroom practices. They feel constraint by lack of material knowledge and time limitations in the curriculum. Although mathematics can be applied in many STEM tasks, the mathematics curriculum and textbooks do not make this explicit, which hinders teachers to recognize the contribution of STEM tasks to mathematics skills development.

\section{ACKNOWLEDGEMENTS}

The study is a part of the second author's master's thesis under the supervision of the first author. The authors would like to thank the editor and the anonymous reviewers.

\section{REFERENCES}

Altun, Y. and Yildirim, B. (2015). Ortaokul STEM etkinlik ve proje kitabı [Middle school STEM activity and project book]. Teoriden pratiğe STEM eğitimi serisi [STEM education series from theory to practice]. Eduplay: Istanbul.

Bergsten, C. and Frejd, P. (2019). Preparing pre-service mathematics teachers for STEM education: An analysis of lesson proposals. ZDM-Mathematics Education, 51(1), 937-953. https://doi.org/10.1007/s11858-019-01071-7

Bicer, A., Navruz, B., Capraro, R. M., Capraro, M. M., Oner, A. T. and Boedeker, P. (2015). STEM schools vs. nonSTEM schools: Comparing students' mathematics growth rate on high-stakes test performance. International Journal on New Trends in Education and Their Implications, 6(1), 138-150.

Buyukozturk, S. (2005). Anket geliştirme [Survey development]. Türk Eğitim Bilimleri Dergisi [Turkish Journal of Educational Sciences], 3(2), 133-151. Available at: https://dergipark.org.tr/tr/pub/tebd/issue/26124/275190

Bybee, R. W. (2010). What is STEM education? New York: American Association for the Advancement of Science. https://doi.org/10.1126/science.1194998

Calder, N. S. (2018). Using Scratch to facilitate mathematical thinking. Waikato Journal of Education, 23(2), 43-58. https://doi.org/10.15663/wje.v23i2.654

Creswell, J. W. (2009). Research design, qualitative, quantitative, and mixed methods approaches. Thousand Oaks, CA: SAGE.

Drake, S. M. (2012). Creating standards-based integrated curriculum: The common core state standards edition. Thousand Oaks, CA: Corwin Press.

El-Deghaidy, H., Mansour, N., Alzaghibi, M. and Alhammad, K. (2017). Context of STEM integration in schools: Views from in-service science teachers. Eurasia Journal of Mathematics, Science, and Technology Education, 13(6), 24592484. https://doi.org/10.12973/eurasia.2017.01235a

English, L. (2016). STEM education: Perspectives on integration. International Journal of STEM Education, $3,3$. https://doi.org/10.1186/s40594-016-0036-1

Estapa, A. T. and Tank, K. M. (2017). Supporting integrated STEM in the elementary classroom: A professional development approach centered on an engineering design challenge. International Journal of STEM Education, 4, 6. https://doi.org/10.1186/s40594-017-0058-3

Iskrenovic-Momcilovic, O. (2020). Improving geometry teaching with Scratch. International Electronic Joumal of Mathematics Education, 15(2), em0582. https:// doi.org/10.29333/iejme/7807

Kang, M., Kim, J. and Kim, Y. (2013). Learning outcomes of the teacher training program for STEAM education. Korean Journal of the Learning Sciences, 7(2), 18-28.

Kelley, T. R. and Knowles, J. G. (2016). A conceptual framework for integrated STEM education. International Journal of STEM Education, 3, 11. https://doi.org/10.1186/s40594-016-0046-z

Kennedy, T. J. and Odell, M. R. L. (2014). Engaging students in STEM education. Science Education International, 25(3), 246-258.

Li, Y., Wang, K., Xiao, Y. and Froyd, J. E. (2020). Research and trends in STEM education: A systematic review of journal publications. International Journal of STEM Education, 7, 11. https://doi.org/10.1186/s40594-02000207-6

Marginson, S., Tytler, R., Freeman, B. and Roberts, K. (2013). STEM: Country comparisons. Report for the Australian Council of Learned Academies. Available at: www.acola.org.au

Margot, K. C. and Kettler, T. (2019). Teachers' perception of STEM integration and education: A systematic literature review. International Journal of STEM Education, 6, 2. https://doi.org/10.1186/s40594-018-0151-2

Ministry of National Education in Turkey. (MoNE, 2016). STEM eğitimi raporu [STEM education report]. Available at: http://yegitek.meb.gov.tr/STEM_Egitimi_Raporu.pdf 
Ministry of National Education in Turkey. (MoNE, 2018). Matematik dersi ögretim programı [Mathematics course curriculum (1-8 grade)]. Available at: http:/ / mufredat.meb.gov.tr/

National Council of Teachers of Mathematics. (NCTM, 2000). Principles and standards for school mathematics. Available at: http://www.nctm.org/uploadedFiles/Standards_and_Positions/PSSM_ExecutiveSummary.pdf

National Research Council. (NRC, 2011). Successful K-12 STEM education: Identifying effective approaches in science, technology, engineering, and mathematics. Committee on highly successful science programs for K-12 science education. Washington, DC: The National Academies Press.

Ozdemir, A. S., Sevimli, E., Aydin, E. and Derin, G. (2018). Examining the opinions of mathematics teacher candidates on the effectiveness of coding activities in the teaching-learning process [Paper presentation]. British Society for Research into Learning Mathematics, King's College, London, UK.

Park, H., Byun, S. Y., Sim, J., Han, H. and Baek, Y. S. (2016). Teachers' perceptions and practices of STEAM education in South Korea. Eurasia Journal of Mathematics, Science \& Technology Education, 12(7), $1739-1753$. https://doi.org/10.12973/eurasia.2016.1531a

Shaughnessy, M. (2013). By way of introduction: Mathematics in a STEM context. Mathematics Teaching in the Middle School, 18(6), 324-326. https://doi.org/10.5951/mathteacmiddscho.18.6.0324

Stohlmann, M. S. (2017). Mathematical modeling with middle school students: The robot art model-eliciting activity. European Journal of STEM Education, 2(2), 4. https:/ / doi.org/10.20897/ ejsteme.201704

Stohlmann, M., Moore, T. and Roehrig, G. H. (2012). Considerations for teaching integrated STEM education. Journal of Pre-College Engineering Education Research, 2(1), 28-34. https:/ / doi.org/10.5703/1288284314653

Tseng, K. H., Chang, C. C, Lou, S. J. and Chen W. P. (2013). Attitudes towards STEM in a project-based learning environment. International Journal Technology Design Education, 23(1), 87-102. https://doi.org/10.1007/s10798011-9160-x

Tsupros, N., Kohler, R. and Hallinen, J. (2009). STEM education: A project to identify the missing components. Intermediate Unit 1: Center for STEM Education and Leonard Gelfand Center for Service Learning and Outreach, Carnegie Mellon University, Pennsylvania.

TUBITAK. (2016). Bilim ve Teknoloji Yülesek Kurulu kararlar ve gelismeleri [Decisions and developments of the Supreme Council of Science and Technology]. Available at: https://tubitak.gov.tr/sites/default/files/btyk29_web_2.pdf

Wang, H., Moore, T. J., Roehrig, G. H. and Park, M. S. (2011). STEM integration: Teacher perceptions and practice. Journal of Pre-College Engineering Education Research, 1(2), 2-23.

Wang, X. (2013). Why students choose STEM majors: Motivation, high school learning, and postsecondary context of support. American Educational Research Journal, 50(5), 1081-1121. https:/ / doi.org/10.3102/0002831213488622

Yildirim, A. and Simsek, H. (2016). Sosyal bilimlerde nitel araştırma yöntemleri [Qualitative research methods in the social sciences]. Ankara: Seçkin Yayıncılık [Seckin Publishing].

Yildirim, B. and Altun, Y. (2015). STEM eğitim ve mühendislik uygulamalarının fen bilgisi laboratuar dersindeki etkilerinin incelenmesi [Investigating the effect of STEM education and engineering applications on science laboratory lectures]. El-Cezerî Fen ve Mühendislik Dergisi [Al-Jazari Journal of Science and Engineering], 2(2), 28-40. 